\title{
Influence of Position of Moving Parts of Lathe on Dynamic Characteristics
}

\author{
Denisenko Alexander \\ Department of Automated Machine Tools and Tool Systems \\ Samara State Technical University \\ Samara, Russia \\ sammortor@yandex.ru
}

\begin{abstract}
A technique and a dynamic model for calculating the own frequencies and forms of oscillations of a lathe with a horizontal plane of guides mounted on rubber-metal supports are proposed. A two-mass dynamic model with 3 degrees of freedom was used, which performs translational-angular oscillations. The mass, formed from the masses of the base, the bed, the headstock and the tailstock, performs both translational and angular vibrations. The mass of the support group performs only translational vertical vibrations. The dynamic model allows to take into account the asymmetric layout of the lathe and the redistribution of the static load on the rubber-metal supports due to the movements of the machine nodes during shaping and adjustment. Based on the processing of the experimental data, a nonlinear dependence of the rigidity of the rubber-metal support on the axial load as a polynomial of the third degree is obtained.

The carried out approbation of the proposed technique showed that for longitudinal displacement of the support group, the variation of the second and third own frequencies can reach $3.5 \%$. The increase in the weight of the support group when the machine is equipped with a multi-position turret increases the range of variation of own frequencies to $5.2 \%$. It is shown that the third own frequency has the greatest influence on the accuracy of processing short blanks, and the second and third own frequencies affect the accuracy of processing long blanks.
\end{abstract}

Keywords - lathe, dynamic model, rubber-metal support, stiffness, own frequency, form of oscillations

\section{INTRODUCTION}

Machining is one of the most common industrial processes in the industry due to its ability to produce high-quality parts with exceptional flexibility. These characteristics have been further aggravated in the last few decades due to the continuous development of science and technology, as well as advanced technological requirements for production [2].

As the industry strives to master micro- and nanoscale levels of high-speed production, high processing precision and super-smooth processing quality must be strictly guaranteed, requiring machine work to smooth with minimal vibration [13].

However, under certain conditions, the process may become unstable yielding oscillations with high amplitudes which result in poor surface finish and damage to the cutting tool, part and the machine too $[6,7]$.

Therefore, the vibration reduction of machine tools is the key technology to guarantee the precision and ultra precision machining. The harm of machine tool vibration is obvious, reduce parts processing precision and quality, cause component wear.

Analysis of the dynamic characteristics of the machine tool is one of the components to ensure the operational characteristics of the machine tool during the design stage [4, $5,8,9]$.

In recent years, a significant number of publications have been devoted to the study of dynamic processes in machine tools [11-17].

Analysis of the values of the natural frequencies of the technological system and vibration modes allows us to choose the rational design and layout solutions of the projected machine tool.

However, some averaged values are often taken into account. This does not allow performing a dynamic analysis of the system with the provision of predictable results and making it difficult to monitor the technical condition of the equipment using a dynamic criterion. In connection with this assessment of the variation of the basic dynamic characteristics of the machine is an urgent task, the solution of which will allow taking into account in the design and diagnostics the features of individual models of machine tools $[4,5,8-10]$.

Varying the dynamic characteristics of the machine can be caused by the fact that, firstly, the layout solution of the machine is generally not symmetrical, and, secondly, there are movements of the machine nodes related to the forming, adjusting and other movements.

The center of gravity of the lathes with the horizontal plane of the guides is shifted to the location of the headstock. When installing the machine on rubber-metal vibrationresistant supports, the asymmetrical arrangement of the center of gravity causes their static deformation, which, with the nonlinear characteristic of supports, must be taken into account [18].

The second feature of such machines is the considerable movement along the guides of the support group (especially in machines with an elongated bed). 


\section{MODELLING APPROACH}

\section{A. Dynamic model}

Taking into account these features, we can use for the dynamic analysis a two-mass design dynamic model with 3 degrees of freedom, which performs translational-angular oscillations (Fig. 1). Mass $m_{0}$, formed from the masses of the base, the frame, the headstock and tailstock, performs both translational and angular vibrations. Mass of the support group $m_{1}$ performs only translational vertical vibrations. The value $l_{2}$ has a certain range of variation, determined by the position of the center of mass $m_{0}$ and the technical capabilities of the machine in terms of the magnitude of the longitudinal movements of the support.

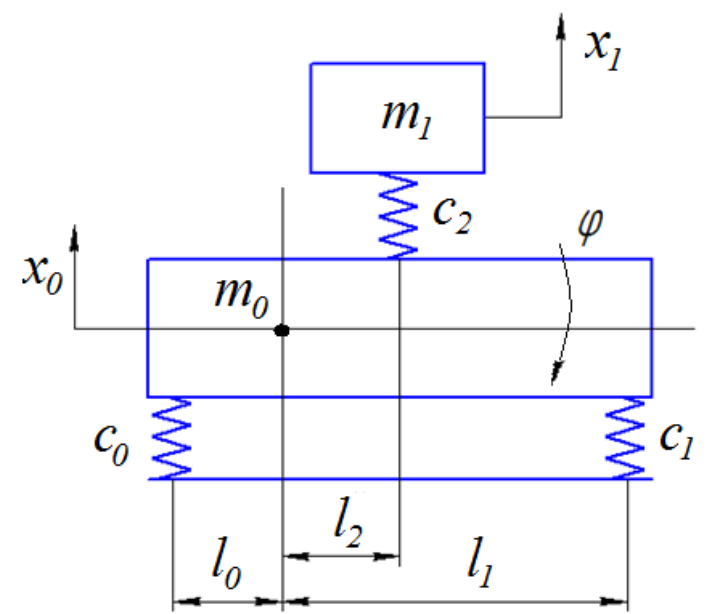

Fig. 1. The translational-angular dynamic model

The equations of motion of a two-mass system (Fig. 1) with translational motions along the coordinates $x_{0}$ and $x_{1}$ and mass rotation $\varphi$ are written in the form of a system of differential equations [19-21]:

$$
M\{\ddot{x}\}+H\{\dot{x}\}+C\{x\}=\{F\},
$$

where $M, H, C$ - inertial, dissipative and elastic matrix, respectively;

$\{x\},\{F\}$ - matrix columns of coordinates and perturbing forces, respectively.

To determine the natural frequencies and modes of vibration by the action of disturbing forces and damping in the system, one can neglect it.

Then equation (1) takes the form:

$$
M\{\ddot{x}\}+C\{x\}=0 \text {. }
$$

For the translational-angular dynamic model under consideration (Fig. 1), the matrices entering into equation (2) have the form [19-21]:

$$
M=\left[\begin{array}{ccc}
m_{0} & 0 & 0 \\
0 & I & 0 \\
0 & 0 & m_{1}
\end{array}\right] ; C=\left[\begin{array}{ccc}
c_{00} & c_{01} & c_{02} \\
c_{01} & c_{11} & c_{12} \\
c_{02} & c_{12} & c_{22}
\end{array}\right] ;\{x\}=\left[\begin{array}{c}
x_{0} \\
\varphi \\
x_{1}
\end{array}\right] \text {, }
$$

where

$$
\begin{aligned}
& c_{00}=c_{0}+c_{1}+c_{2} ; \\
& c_{01}=c_{0} l_{0}+c_{1} l_{1}-c_{2} l_{2} ; \\
& c_{02}=-c_{2} ; \\
& c_{01}=c_{0} l_{0}+c_{1} l_{1}-c_{2} l_{2} ; \\
& c_{11}=c_{0} l_{0}^{2}+c_{1} l_{1}^{2}+c_{2} l_{2}^{2} ; \\
& c_{12}=c_{2} l_{2} ; c_{02}=-c_{2} ; \\
& c_{12}=c_{2} l_{2} ; c_{22}=c_{2} .
\end{aligned}
$$

The squares of the system's own circular frequencies are found from the solution of the characteristic cubic equation:

$$
a_{0} \cdot\left(\omega^{2}\right)^{3}+a_{1} \cdot\left(\omega^{2}\right)^{2}+a_{2} \cdot \omega^{2}+a_{3}=0,
$$

where coefficients $a_{0} ; a_{1} ; a_{2} ; a_{3}$ are determined by the formulas:

$$
\begin{aligned}
& a_{0}=-m_{0} m_{1} m_{2} ; \\
& a_{1}=m_{1} m_{2} c_{00}+m_{0} m_{2} c_{11}+m_{0} m_{1} c_{22} ; \\
& a_{2}=m_{1} c_{02} c_{20}+m_{0} c_{12} c_{21}+m_{2} c_{01} c_{10}-m_{2} c_{00} c_{11}- \\
& -m_{1} c_{00} c_{22}-m_{0} c_{11} c_{22} ; \\
& a_{3}=c_{02} c_{10} c_{21}+c_{20} c_{01} c_{12}-c_{11} c_{02} c_{20}-c_{00} c_{12} c_{21}- \\
& -c_{22} c_{01} c_{10}+c_{00} c_{11} c_{22} .
\end{aligned}
$$

Consider the definition of dynamic characteristics using the proposed model using the example of the "Vector" lathe of CJSC "Srednevolzhskiy Machine Tools" (Samara).

The inertial characteristics are determined by the preliminary sketches of the headstock, base, frame, tailstock and support group.

Sketches are represented in the form of a set of figures of a simple geometric form (parallelepipeds, cylinders) for which it is not difficult to calculate the volumes of the nodes considered by their overall dimensions. For example, Fig. 2 shows the sketch of the support group of the machine (without an apron and toolholder).

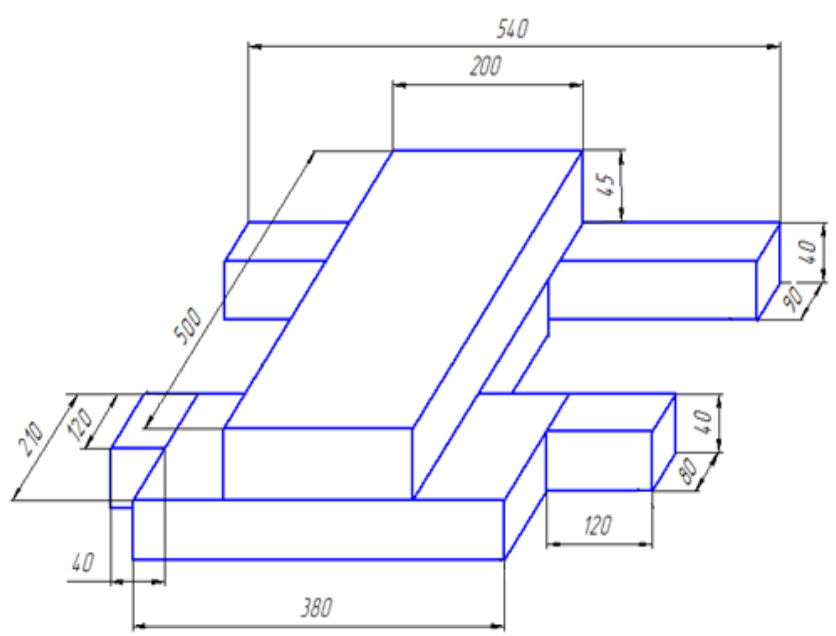

Fig. 2. Sketch of a support group 
When determining the mass of the elements of the machine carrier system to take into account the incomplete filling of the volume, the coefficient equal to the front headstock and the frame $\theta=0.5$ was used, and for the base $\theta=0.3 \ldots 0.5$ :

$$
m=V \theta \rho,
$$

where $V$ - the volume of the node;

$\rho$ - the density of the material.

Thus, for the machine "Vector": $m_{0}=1966 \mathrm{~kg} ; I=798$ $\mathrm{kg} \cdot \mathrm{m}^{2} ; m_{1}=127 \mathrm{~kg} ; l_{0}=0.827 \mathrm{~m}$ and $l_{1}=1.108 \mathrm{~m}$.

When longitudinal movement of the machine support is $700 \mathrm{~mm}$, the value $l_{2}$ changes from $-0.027 \mathrm{~m}$ to $0.673 \mathrm{~m}$.

Bearing in mind that during operation the machine is installed on four supports located at the corners of the bearing surface, the load taking into account the movement of the support:

- on each left support, is:

at the leftmost position of the support group $R_{l}=6000 \mathrm{~N}$;

at the rightmost position of the support group $R_{r}=5770$ $\mathrm{N}$;

- for each right support, is:

at the leftmost position of the support group $R_{l}^{\prime}=4467 \mathrm{~N}$;

at the rightmost position of the support group $R_{r}^{\prime}=4695$ N.

\section{B. Elastic characteristics of the rubber-metal support}

Earlier [22], when testing rubber-metal supports, data were obtained that made it possible to construct an average graph of the change in the axial deformation of the support from the applied load (Fig. 3).

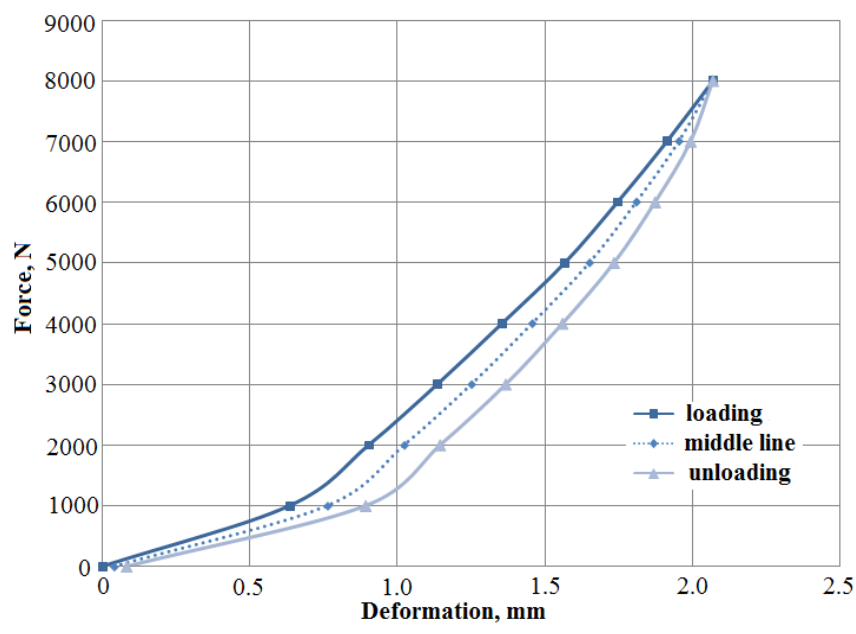

Fig. 3. Dependence of the elastic deformations of the rubber-metal support on the applied axial force

Fig. 4 shows the graph of the axial stiffness of the support, constructed for the values of the midline (Fig. 3), which confirms the nonlinear character of the dependence of stiffness on the axial load.
To determine the dependence that adequately describes this characteristic, the Excel package was used, which allows building a trend depending on the type of approximating dependence. The results of approximating the experimental curve in Fig. 4 are given in Table I.

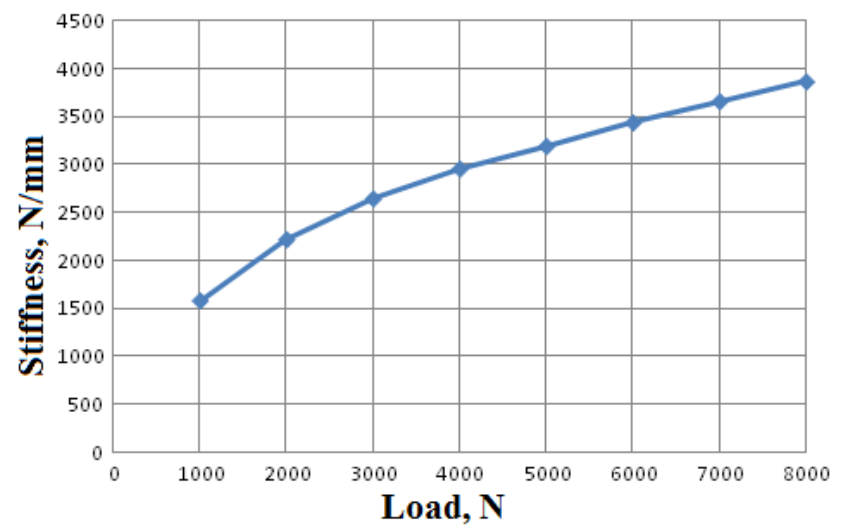

Fig. 4. Dependence of the axial stiffness of the rubber-metal support on the applied force

TABLE I. APPROXIMATIONS OF THE EXPERIMENTAL DEPENDENCE

$$
c=f(P), \mathrm{N} / \mathrm{MM}
$$

\begin{tabular}{|l|l|c|}
\hline $\begin{array}{c}\text { Approximation } \\
\text { type }\end{array}$ & \multicolumn{1}{|c|}{ Approximating dependence } & $R^{2}$ \\
\hline linear & $c=0.3081 P+1557$ & 0.958 \\
\hline degree & $c=86.43 P^{0.4242}$ & 0.997 \\
\hline logarithmic & $c=1092 \ln P-6052$ & 0.993 \\
\hline $\begin{array}{l}\text { polynomial } \\
(\mathrm{n}=2)\end{array}$ & $\begin{array}{l}c=-2.979 \cdot 10^{-5} P^{2}+0.5762 P+ \\
+1110\end{array}$ & 0.994 \\
\hline $\begin{array}{l}\text { polynomial } \\
(\mathrm{n}=3)\end{array}$ & $\begin{array}{l}c=6.438 \cdot 10^{-9} P^{3}-1.167 \cdot 10^{-4} P^{2}+ \\
+0.9078 P+791.1\end{array}$ & 0.999 \\
\hline
\end{tabular}

As the best approximation one chooses one in which the deviation between the model and the real data is minimal. For this, the deterministic coefficient $R^{2}$ is used (the coefficient of reliability of the approximation, or the level of reliability). The best is the dependence that $R^{2}$ is more important. Comparison of the dependencies of Table 1 shows that the most adequate description of the characteristic of the axial rigidity of a rubber-metal support is the polynomial dependence $n=3$.

\section{RESULTS AND DISCUSSIONS}

When using this polynomial dependence, taking into account the movement of the support of the machine, we have:

at the leftmost position of the support group $c_{0}=6.855 \cdot 10^{6}$

$\mathrm{N} / \mathrm{m}$ and $c_{1}=6.183 \cdot 10^{6} \mathrm{~N} / \mathrm{m}$;

at the rightmost position of the support group $c_{0}=6.761 \cdot 10^{6} \mathrm{~N} / \mathrm{m}$ and $c_{1}=6.294 \cdot 10^{6} \mathrm{~N} / \mathrm{m}$. 
The stiffness $c_{2}$ is determined by the stiffness of the movable joint of the support group of the machine with the bed in the longitudinal guides:

$$
c_{2}=c_{2}^{\prime}+c_{2}^{\prime \prime},
$$

where $c_{2}^{\prime}$ - the stiffness of the movable joint in the prismatic guide;

$c_{2}^{\prime \prime}$ - the stiffness of the movable joint in a flat guide.

Assuming that the elastic approaches in the joint $\delta$ are proportional to the normal pressures $\sigma$ [30]: $\delta=k \sigma$, where $k$ - the coefficient of contact susceptibility, depending on the size of the joint, the stiffness of the movable joints $c_{2}^{\prime}$ and $c_{2}^{\prime \prime}$, $\mathrm{N} / \mathrm{m}$, can be determined from formulas:

$$
c_{2}^{\prime}=\frac{F^{\prime}}{k^{\prime}} ; c_{2}^{\prime \prime}=\frac{F^{\prime \prime}}{k^{\prime \prime}},
$$

where $F^{\prime} ; F^{\prime \prime}$ - the area of the movable joint of the prismatic and flat guide, respectively, $\mathrm{m}^{2}$;

$k^{\prime} ; k^{\prime \prime}$ - coefficients of contact compliance of the prismatic and flat guides, respectively, $\mathrm{m}^{3} / \mathrm{N}$.

Taking into account the parameters of the longitudinal guides of the "Vector" machine (the angle of inclination of the prismatic guide rail is $45^{\circ}$, the width of the prismatic guide rail is $25 \mathrm{~mm}$, the width of the face of the flat guide is $23 \mathrm{~mm}$, the length of the carriage guides is $510 \mathrm{~mm}$ ), the rigidity $c_{2}$ is $2.718 \cdot 10^{9} \mathrm{~N} / \mathrm{m}$.

For the obtained initial data, the dynamic model (2) gives the natural frequencies of the system, given in Table II.

TABLE II. OWN FREQUENCIES OF THE MACHINE "VECTOR", Hz

\begin{tabular}{|c|c|c|c|c|c|}
\hline \multicolumn{2}{|c|}{ Left position of the support group } & \multicolumn{3}{c|}{ Right position of the support group } \\
\hline$f_{l 1}$ & $f_{l 2}$ & $f_{l 3}$ & $f_{r 1}$ & $f_{r 2}$ & $f_{r 3}$ \\
\hline 12.467 & 19.804 & 759.737 & 12.52 & 19.123 & 785.011 \\
\hline
\end{tabular}

Estimating the variation of the own frequencies by the relation:

$$
\Delta_{f i}=\left|\frac{2\left(f_{l i}-f_{r i}\right)}{\left(f_{l i}+f_{r i}\right)}\right|
$$

we get:

$$
\Delta_{f 1}=0.004 ; \quad \Delta_{f 2}=0.035 ; \quad \Delta_{f 3}=0.033 .
$$

When equipping the machine with a multi-position turret (16B16T1 machine), the weight of the support group increases to $200 \mathrm{~kg}$. The own frequencies of the 16B16T1 machine are given in Table III. Varying the own frequencies is:

$$
\Delta_{f 1}=0.006 ; \quad \Delta_{f 2}=0.052 ; \quad \Delta_{f 3}=0.049 .
$$

TABLE III. OWN FREQUENCIES OF THE MACHINE 16B16T1, HZ

\begin{tabular}{|c|c|c|c|c|c|}
\hline \multicolumn{2}{|c|}{ Left position of the support group } & \multicolumn{3}{c|}{ Right position of the support group } \\
\hline$f_{l 1}$ & $f_{l 2}$ & $f_{l 3}$ & $f_{r 1}$ & $f_{r 2}$ & $f_{r 3}$ \\
\hline 12.33 & 19.923 & 615.903 & 12.403 & 18.909 & 646.832 \\
\hline
\end{tabular}

The forms of oscillations are shown in Fig. 5 and Fig. 6 when the vectors are normalized (we take the vector that determines the displacement of the mass $m_{0}$, equal to 1 ). From Fig. 5 and Fig. 6 it follows that the displacement of the mass $m_{1}$ relative to the mass $m_{0}$, directly affecting the accuracy of the processing with the left position of the support group affects only the third own frequency $f_{3}$. As the support group moves from the headstock to the tailstock, the relative displacements of masses $m_{0}$ and $m_{1}$ become significant not only at the third own frequency $f_{3}$, but also at the second own frequency $f_{2}$. The increase in the weight of the support group affects the frequency $f_{2}$.

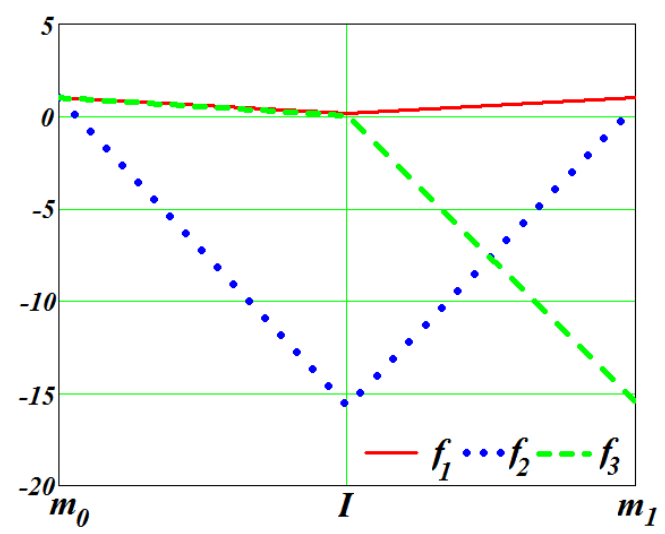

a)

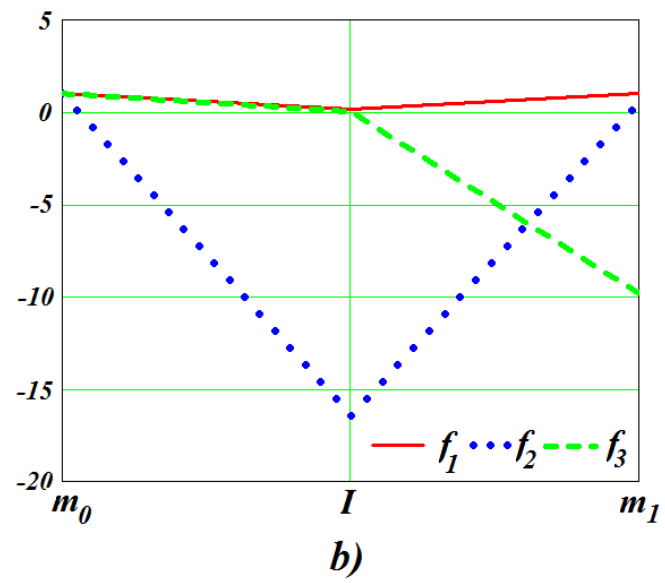

Fig. 5. Forms of oscillations: $a$ - the left position of the support group; $b$ - the left position of the support group of increased mass 

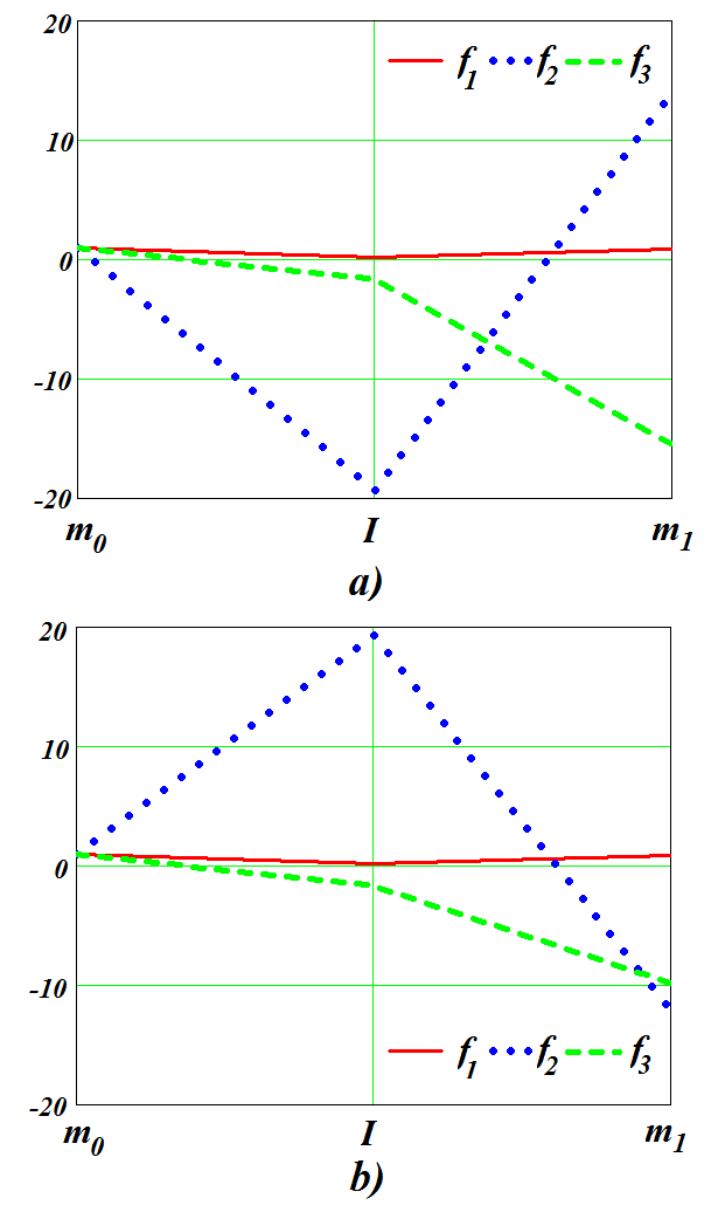

Fig. 6. Forms of oscillations: $a$ - the right position of the support group; $b$ the right position of a support group of the increased weight

\section{CONCLUSION}

A technique and a dynamic model that take into account the asymmetrical arrangement and redistribution of the static load on the rubber-metal supports due to the movements of the machine nodes, for the calculation of own frequencies and forms of oscillations is proposed. Based on the processing of the experimental data, a nonlinear dependence of the rigidity of the rubber-metal support on the axial load as a polynomial of the third degree. The carried out approbation of the proposed technique with the example of a lathe with a horizontal plane of guides mounted on rubber-metal supports showed that during longitudinal movement of the support group, the variation of the second and third own frequencies can reach $3.5 \%$. The increase in the weight of the support group when the machine is equipped with a multi-position turret increases the range of variation of natural frequencies to $5.2 \%$. From the point of view of the influence of dynamic processes on the accuracy of processing, the third most natural frequency is the most dangerous when processing short blanks, and when processing long blanks - the second and third own frequencies.

\section{References}

[1] Brandon C. Gegg, C. Steve Suh, Albert C.J. Luo. Machine Tool Vibrations and Cutting Dynamics. Springer New York Dordrecht Heidelberg London, 2011. DOI 10.1007/978-1-4419-9801-9.

[2] Erhan Budak, "Machining Stability and Machine Tool Dynamics",11 International Research/Expert Conference "Trends in the Development of Machinery and Associated Technology" TMT 2007, Hammamet, Tunisia, 5-9 September, 2007

[3] L. Chunmei and L. Weina, "Semi-active Fuzzy Control for Machine Tool Vibration", International Conference on Mechanics, Materials and Structural Engineering (ICMMSE 2016).

[4] V. Bushuev, A. Kuznetsov, F. Sabirov, V. Khomyakov, V. Molodtsov, "Precision and Efficiency of Metal-cutting Machines", Russian Engineering Research, 2016, vol. 36, No. 9, pp. 762-773.

[5] V. Bushuev, A. Kuznetsov, F. Sabirov, V. Khomyakov, V. Molodtsov, "Trends in Research on Metal-cutting Machines", Russian Engineering Research, 2016, vol. 36, No. 6, pp. 488-495.

[6] M. Wiercigroch, "Chaotic vibration of a simple model of the machine tool-cutting process system", Transactions of the ASME: Journal of Vibration and Acoustics, 119, 1997, pp. 468-475.

[7] G. Bianchi, S. Cagna, N. Cau, F. Paolucci, "Analysis of vibration damping in machine tools", Procedia CIRP 21, 2014, pp. 367 - 372.

[8] N. Cau, M. Leonesio, E. Zanotti, P. Parenti, G. Bianchi, "Integrated Machine Tool Design", Proc of the 2nd Int Researchers Symposium 2009 on Innovative Production Machines and Systems (IPROMS). Ischia (Italy), 22-24 July.

[9] G. Bianchi, F. Paolucci, P. Van den Braembussche, H. Van Brussel, "Towards Virtual Engineering in Machine Tool Design", Annals of CIRP, vol. 45/1,1996.

[10] Mouleeswaran Senthilkumar, Moorthy Vikram and Bhaskaran Pradeep, "Vibration Monitoring for Defect Diagnosis on a Machine Tool: A Comprehensive Case Study, (pp. 4_9) International Journal of Acoustics and Vibration, vol. 20, No. 1, 2015, pp. 4-9.

[11] S. Cornelius and G. Paresh. Practical Machinery Vibration Analysis and Predictive Maintenance, Elsevier, 2004.

[12] Ming-zhang Ren. Analysis and control and the calculation methods of mechanical vibration. China Machine Press:Beijing, 2011.

[13] I. Zaghbani and V. Songmene,"Estimation of machine-tool dynamic parameters during machining operation through operational modal analysis", International Journal of Machine Tools and Manufacture, 49(12), 2009, pp.947-957.

[14] M. Siddhpura and R. Paurobally, R. (2012) "A review of chatter vibration research in turning", International Journal of Machine Tools\&Manufacture, vol. 61, 2012, pp. 27-47.

[15] S. Choudhury,N. Goudimenko, V. Kudinov, (1997) "On-line control of machine tool vibration in turning", International Journal of Machine Tools\&Manufacture, vol. 37(6), 1997, pp. 801-811.

[16] S. Abuthakeer, P. Mohanram, G. Mohan Kumar, "Prediction and Contour of Cutting to Vibration in CNC Lathe with Anova and Ann", International Journal of Lean Thinking, vol. 2, No. 1, pp. 2526-2537.

[17] I. Puertas, C. Luis Pérez, "Surface roughness prediction by factorial design of experiments in turning processes", Journal of Materials Processing Technology, No.143-144, 2003, pp. 390-396.

[18] Vibrations in technology: Handbook. In 6 tons / Ed. Advice: V. N. Chelomei (prev.). - Moskow: Mechanical Engineering, 1981. - V. 6. Protection from vibration and shock, Ed. K.V. Frolov. 1981.- 456 p.

[19] Ya. Panovko. Introduction to the theory of mechanical oscillations. Moscow: Nauka, 1971. 240 p.

[20] Ya. Panovko. Fundamentals of the applied theory of oscillation and impact. - Leningrad: Mechanical Engineering, 1976. 320 p.

[21] V. Biderman. Applied theory of mechanical oscillations. - Moscow: Higher School, 1972. 416 p.

[22] A. Denisenko, M. Yakimov, E. Mazanova, "Determination of axial rigidity of a vibration-resistant rubber-metal support", Materials Vseros. N.t. conference "High technologies in engineering", Samara, 2016, pp. 69-71. 